\title{
Aspectos radiográficos e tomográficos de hemangiossarcoma de meninges causando síndrome da cauda eqüina em um Pastor Alemão
}

\author{
Radiographic and tomographic aspects of meningeal hemangiosarcoma in a German Shepherd dog with \\ clinical signs of cauda equina sindrome
}

\author{
Ana Carolina Brandão de Campos Fonseca PintoI Cássio Ricardo Auada Ferrigno ${ }^{\mathrm{I}}$ \\ Júlia Maria Matera ${ }^{\mathrm{I}}$ Luciana N. Torres ${ }^{\mathrm{II}}$ Idércio L. Sinhorini ${ }^{\mathrm{III}}$ Silvia Renata Gaido Cortopassi ${ }^{\mathrm{I}}$ \\ Maria Cristina Ferrarini Nunes Soares Hage ${ }^{\mathrm{IV}}$
}

\begin{abstract}
O hemangiossarcoma é uma neoplasma altamente maligna da linha de células endoteliais e que, portanto, pode ter origem em qualquer tecido com vasos sangüíneos. Descreve-se um caso raro de hemangiossarcoma de meninge em um cão Pastor Alemão de 8 anos de idade, com manifestações clínicas de síndrome da cauda eqüina. $O$ diagnóstico foi realizado com base nos achados clínicos, radiográficos, tomográficos e histopatológicos.

Palavras-chave: hemangiossarcoma, cães, tomografia computadorizada, mielografia, meninges, síndrome da cauda eqüina.
\end{abstract}

\section{ABSTRACT}

Hemangiosarcoma is a highly malignant neoplasia derived from the endothelial cell line and, therefore, can arise in any tissue with blood vessels. A case of a rare meningeal site of hemangiosarcoma in an eight-year old German Shepherd dog with clinical signs of cauda equina sindrome is described. The diagnosis was made based on clinical, radiographic, tomographic and histopathological findings.

Key words: hemangiosarcoma, dogs, computed tomography, mielography, meninges, cauda equina sindrome.
A cauda eqüina é um feixe de raízes nervosas no interior do canal vertebral lombo-sacro. Inicia-se caudal ao final da medula espinhal, entre L5-L6, em cães de grande porte (MORGAN et al., 1987). A síndrome da cauda eqüina manifesta-se como um grupo de manifestações clínicas quando há comprometimento nessa região. As deficiências neurológicas decorrentes da síndrome são uma combinação de sinais de lesão do neurônio motor inferior de L7 (BRAUND, 1994). Por causa da grande variedade de doenças que podem causar a síndrome da cauda eqüina e pelo número de estruturas anatômicas que podem estar envolvidas, determinar a causa freqüentemente requer vários procedimentos diagnósticos (MORGAN \& BAILEY, 2000).

Um Pastor Alemão macho de 8 anos de idade foi atendido no Hospital Veterinário da FMVZ-USP apresentando atonia da cauda, atonia vesical, ataxia locomotora, hiporreflexia espinhal e proprioceptiva dos membros pélvicos e sensibilidade severa em região lombo-sacra. O animal foi submetido ao RX simples, à mielografia e à tomografia computadorizada (TC) da

IDepartamento de Cirurgia, Faculdade de Medicina veterinária e Zootecnia (FMVZ), Universidade de São Paulo (USP). São Paulo, SP, Brasil. E-mail: anacarol@usp.br. Autor para correspondência.

IIServiço de Patologia Animal, HOVET, FMVZ, USP, São Paulo, SP, Brasil.

IIIDepartamento de Patologia Animal, FMVZ, USP, São Paulo, SP, Brasil.

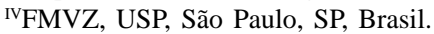


coluna vertebral. O RX simples demonstrou osteófito ventral em face cranial de L4 e discreta diminuição do espaço intervertebral entre L5-L6. A mielografia realizada por meio de punção cervical denotou adelgaçamento das colunas de contraste a partir de L1 e interrupção de sua progressão a partir de L4-L5, caracterizando um padrão de lesão intra-medular, porém não sendo possível, somente por meio desse exame, o estabelecimento do diagnóstico definitivo (Figura 1). Através da TC pós-mielografia realizada em cortes transversais de $5 \mathrm{~mm}$ de espessura das regiões tóracolombar, lombar e lombo-sacra, notou-se atenuação da coluna de contraste entre L3-L4 e L4-L5 e sua ausência entre L5-L6, L6-L7 e L7-S1 (Figura 2), com presença de material com atenuação de partes moles ocupando todo o canal vertebral, além de dois pontos de calcificação em assoalho ventro-lateral à direita do canal vertebral entre L5-L6 (Figura 3). Tais achados indicaram a presença de uma neoformação no canal vertebral sem, contudo, poder excluir a presença de protrusão de disco intervertebral entre L5-L6. O animal foi submetido à laminectomia dos processos transversos de L5-L6 que confirmou a presença de uma massa comprimindo a medula, sendo que o exame histopatológico transoperatório possibilitou o diagnóstico de hemangiossarcoma de meninge como causador da síndrome da cauda eqüina. A excisão tumoral não foi factível e o proprietário optou pela eutanásia do animal.

O hemangiossarcoma é uma neoplasia altamente maligna derivada da linhagem de células endoteliais e caracterizada por metástases precoces e agressivas. A idade média de ocorrência é de 8 a 13 anos, e os cães da raça Pastor Alemão parecem ser predispostos (BROWN et al., 1985; SMITH, 2003). O hemangiossarcoma pode ter origem em qualquer tecido com vasos sangüíneos, mas os locais mais comuns são o baço (50-60\%), o átrio direito (3-25\%), o tecido subcutâneo (13-17\%) e o fígado. Outros locais primários descritos incluem a pele, o pulmão, a aorta, os rins, a cavidade oral, os músculos, os ossos, a bexiga, os intestinos, a língua, a próstata, a vulva, a vagina, a conjuntiva e o peritônio (BROWN et al., 1985; SMITH, 2003).

Em mais de $80 \%$ dos pacientes, são evidenciadas metástases no momento da apresentação clínica. As metástases mais comuns são no fígado, no omento, no mesentério e no pulmão, embora também sejam descritas nos rins, nos músculos, no peritônio, nos linfonodos, nos ossos, na glândula adrenal, nos olhos, na próstata e no cérebro (BROWN et al., 1985; SMITH, 2003).

A despeito das possibilidades de tratamento paliativo (cirurgia agressiva, quimioterapia ou radioterapia), a perspectiva média de sobrevida é curta para os cães com hemangiossarcoma, sendo que menos de $10 \%$ atingem um ano de sobrevida. (BROWN et al., 1985; SMITH, 2003).

A importância deste relato se deve à localização pouco freqüente do hemangiossarcoma em meninges e pela complementação do exame de TC ao exame radiográfico convencional, proporcionando o estabelecimento do diagnóstico de massa no canal vertebral que não pôde ser realizado pelo exame radiográfico isoladamente.

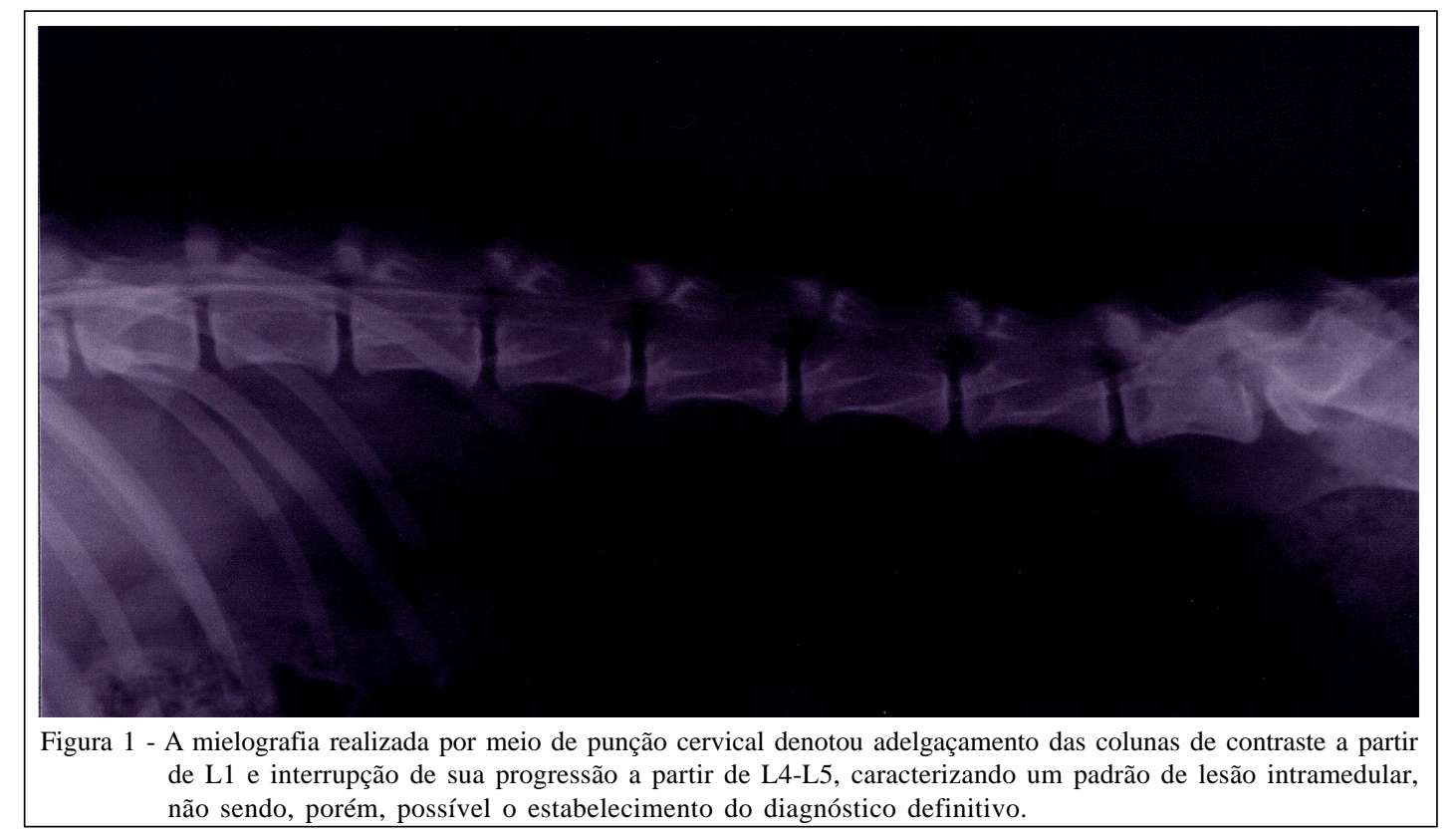

Ciência Rural, v.37, n.2, mar-abr, 2007. 


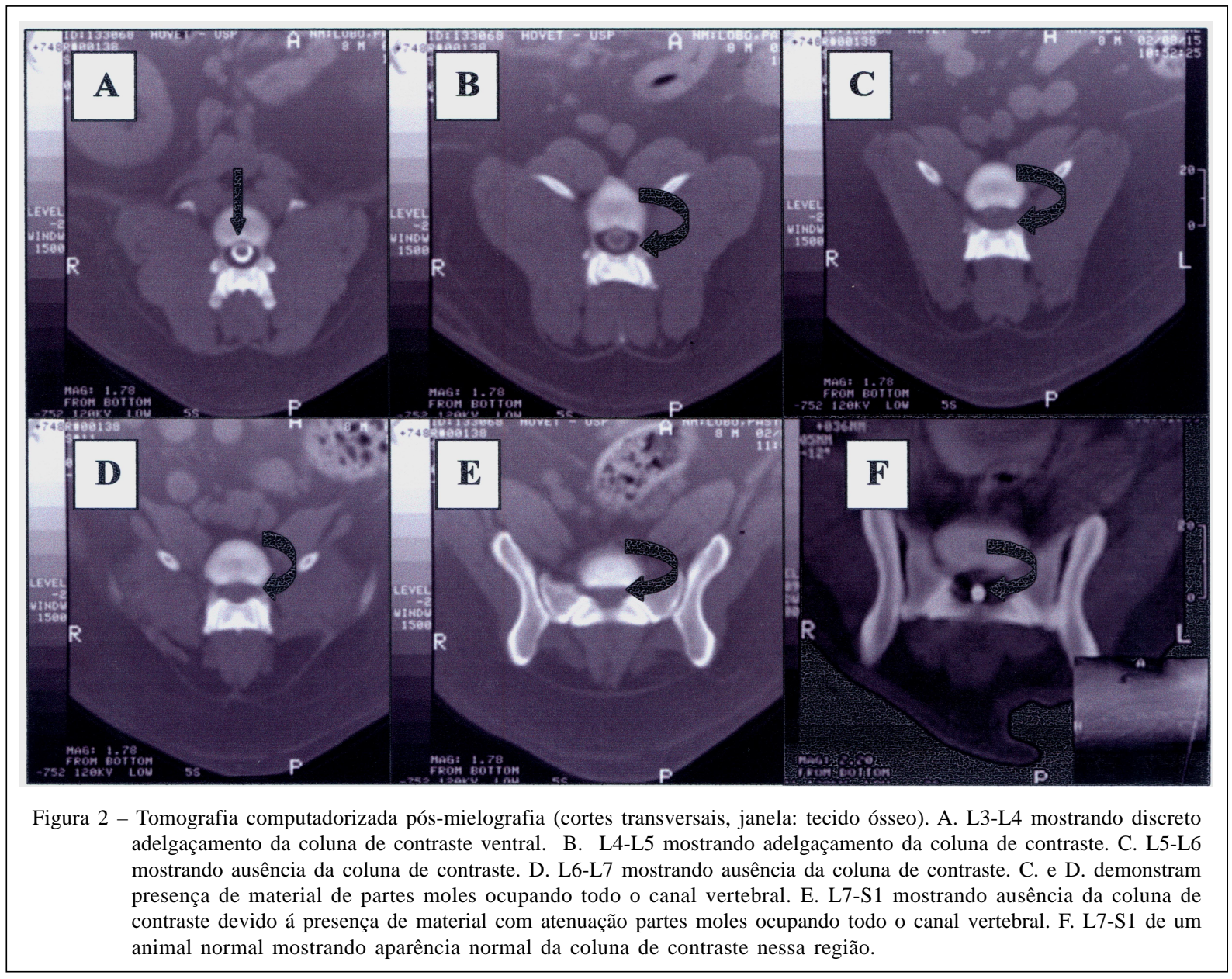

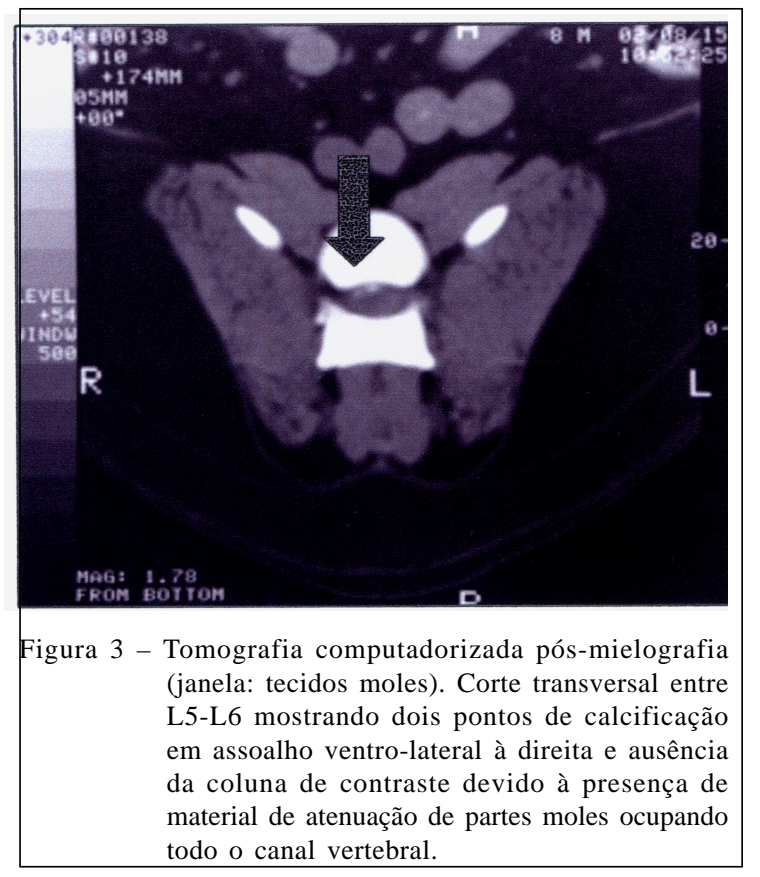

\section{REFERÊNCIAS}

BRAUND, K.G. Clinical syndromes in veterinary neurology. Missouri: Mosby, 1994. 257p.

BROWN, N.O. et al. Canine hemangiosarcoma: retrospective analysis of 104 cases. Journal of the American Veterinary Medical Association, v.186, n.1, p.56-58, 1985.

MORGAN, J.P. et al. Vertebral canal and spinal cord mensuration: a comparative study of its effect on lumbosacral myelography in the Dachshund and German Shepherd dog. Journal of the American Veterinary Medical Association, v.191, n.8, p.951-957, 1987.

MORGAN, J.P.; BAILEY, C.S. Exercises in veterinary radiology - spinal disease. Iowa: Iowa State, 2000. 325p.

SMITH, A.N. Hemangiosarcoma in dogs and cats. Veterinary Clinics of Small Animal Practice, v.33, n.3, p.533-552, 2003.

Ciência Rural, v.37, n.2, mar-abr, 2007. 